\title{
Teoria e Prática da Análise Documental
}

\section{Alcides de Albuquerque Reis e Silva}

Técnico de Administração; Adjunto da Secretaria Particular do Presidente da República; Funcionário do Banco do Brasil S.A.

S U M A R I O: I - Introdução. Métodos de análise documental. Métodos quantitativos. Aplicaçăo simulada dos métodos quantitativos na área da Administração Pública; II - Teoria. Categoria de métodos quantitativos. Semântica quantitativa: pesquisa de estilo. Análise do conteúdo: pesquisa das idéias. Técnicas da análise do conteúdo; III - Prática. O universo das mensagens. Metodologia. Categorias de Origem. Categorias de Pessoas. Categorias de Matéria. Categorias de Apreciação. Codificação. Tabulação; IV - Conclusões. Resultados qualitativos: quem escreve, de onde escreve, sobre o que escreve, em que posição se coloca em torno das áreas politica, psicossocial e econômica. Resultados quantitativos: tabulações avançadas; V Bibliografia Especializada. Allport, Berelson, Boulanger, Duverger, Gottschalk, Lasswell, Leites, Marques de Melo, Schultz,
Weingas, White, Wyant.

\section{I - INTRODUÇÃO}

$O$ advento das Ciências da Informação veio inegavelmente estabelecer os pródromos de uma nova técnica que se expande e aperfeiçoa a cada momento, propiciando a adoção de métodos e sistemas tendentes a valorizar a Comunicação nos seus
diversos e infindáveis meandros.

No campo da análise documental, poder-se-ia dizer que, na atualidade, um novo instrumento de apreciação do comportamento das massas começa a ser descoberto: a valorização do
pronunciamento individual nas mensagens grafadas, que revelam 
as aspirações de cada pessoa, mas que são quase sempre consentâneas com os desejos coletivos.

Daí, não mais se relegarem à bolorenta placidez dos arquivos cartas e documentos antes meramente entendidos como simples meios de retransmissão de um recado ou de uma idéia; nem tampouco se classificarem o jornal, o livro e as missivas como apoucados instrumentos de divulgação de temas especificos. Ao contrário, qualquer expressão ou palavra escrita, dirigida a alguém ou a um conjunto de pessoas - por mais elementares que possam parecer - , não raro encerram um vasto manancial passivel de investigação e análise, de modo a facultar medidas que respondam ao benefício geral.

Os processos de análise de documentos obedecem a duas primeiras categorias de métodos: clássicos e quantitativos. Nos métodos clássicos, derivados da crítica literária e da crítica histórica, temos o princípio da intensividade, que manda extrair o máximo conteúdo de um único documento. Nos métodos quantitativos, derivados de técnicas aritméticas, vigem as normas da extensividade, que determinam a extração da essência basilar de uma série de documentos.

Ambos os métodos não se excluem mutuamente: completam-se quando o objetivo analítico visa à apreensão integral da mensagem transmitida no documento. Nesse caso, o subjetivismo dos métodos clássicos - decorrentes da interpretação individual - tempera-se à objetividade dos métodos quantitativos, resultantes do julgamento coletivo (equipes integradas) ou da interveniência de ordenadores eletrônicos. As equipes integradas, reunindo uma diversidade de culturas, favorecem a identificação do interrelacionamento dos fenômenos, resultando na visão global de suas causas e efeitos; possibilitam, por isso, um sistema de muito maior eficácia na recuperação de informes que passariam desapercebidos à observação de um único elemento. $\mathrm{E}$ os modernos equipamentos de processamento de dados permitem os registros quantitativos em larga escala, tomando por modelo a memória, a atenção e outras funções do homem, com a vantagem da velocidade, em níveis vertiginosos com que o cérebro humano não pode competir. Note-se, contudo, que as grandes conquistas da Cibernética não dispensam a supervisão da mente do pesquisador, porque só esta é capaz de apreciar os aspectos qualitativos da informação, selecionando-os com apuro, dentro das necessidades e implicações do momento. 
Detenhamo-nos, agora, nos métodos quantitativos de análise documental, sob o duplo aspecto teórico e prático, que constituem o objetivo deste artigo. São eles os mais preferidos, na área da Administração Pública, porque favorecem sobremodo a unificação do conjunto de dados, levando à apreciação final, com toda a autenticidade, o somatório dos temas tratados, sem tisná-los com interpretações individuais. Tal sistematologia garante a transmissão, para apreciações qualitativas, das informações que fluem espontâneas e que vão muitas vezes completar aquelas que chegam por intermédio dos órgãos técnicos e pelos serviços de inteligência, daí permitindo decisões adequadas e tempestivas.

Desse modo, o resultado da análise global, em termos estatísticos, revela quem escreve, de onde escreve, sobre o que escreve e em que posição se coloca através dos vários canais de comunicação.

\section{II - Teoria. Categorias de Métodos Quantitativos. Análise do Conteúdo.}

São conhecidas duas classes de métodos quantitativos, conforme se relacionem (a) ao estudo do vocabulário, dos modos de expressão, do estilo - caso em que se definem como "semântica quantitativa" - ou (b) se voltem principalmente para o sentido das palavras - caso em que se classificam como "análise do conteúdo".

A semântica quantitativa consiste, essencialmente, em comparar a freqüência das palavras empregadas por certo autor com a frequêencia das palavras do vocabulário corrente de seu tempo. A diferença de freqüência, apurada por métodos estatísticos, indicará as características e, no mesmo passo, as peculiaridades ou a lei de formação do estilo do autor. A gramática e a retórica prestam-se admiravelmente ao método. Antes do confronto e do tratamento quantitativo, o texto do autor é decomposto em palavras, segundo as partes da oração ou do discurso: substantivo, artigo, adjetivo, numeral, pronome, verbo, advérbio, preposição, conjunção e interjeição.

A semântica quantitativa foi empregada com sucesso retumbante pelo Padre Busa no restabelecimento das passagens que faltam aos "manuscritos do Mar Morto". Baseado nas re- 
gras da periodicidade e da associação de palavras (predominância no emprego das partes da oração e modo de as associar), e auxiliado por computador eletrônico, logrou o jesuíta italiano restabelecer, sem erro, até 5 palavras consecutivas dos períodos, omissas naqueles célebres documentos bíblicos.

A análise do conteúdo - forma esquematizada da semântica quantitativa, de emprego mais fácil e rápido - pesquisa menos o estilo do que as idéias do texto. As unidades de análise não são as palavras (partes do discurso) e, sim, significados, temas, frases, parágrafos, os documentos inteiros; e não requerem necessariamente máquinas eletrônicas: podem ser usados processos artesanais.

A técnica de análise do conteúdo é simples. O ponto de partida é a escolha da unidade de análise e a determinação das categorias. Em seguida, procede-se à classificação, de modo tão impessoal quanto possível, e, afinal, ao tratamento matemático dos números obtidos: medianas, percentagens, correlações, etc.

As unidades de análise podem ser classificadas em dois grupos: unidades de base gramatical (palavra, frase ou tema e parágrafo) e unidades de base não gramatical (caracteres, espaço, documento inteiro). A unidade de análise do presente estudo é a carta, não obstante sejam cuidadosamente perquiridos oș temas.

Exemplos célebres de uso de unidades de análise de base gramatical: estudo, por Lasswell, do paralelismo entre a propaganda nazista e os temas utilizados pelos jornais "Bund", bem como os trabalhos de Berelson e Grazie, mostrando as reações causadas nas rádios de Berlim e Londres pelos discursos de Churchill.

Exemplos do grupo de unidades de análise de base não gramatical serão aduzidos ao ensejo do exame das categorias, a ser sucintamente exposto nas linhas abaixô.

Os principais tipos de categorias gerais que têm sido usados na análise do conteúdo são os de matéria, apreciação, pessoas, atores, origem e forma. Entre as categorias de matéria sugeridas, destacam-se as de Lasswell para a análise dos fenômenos políticos e administrativos: as pessoas (homens politicos); grupos e comunidades (americanos, semitas, partidos, etc.); 
as organizações (o Congresso, a Corte Suprema, etc.); a política (guerra, paz, reforma, etc.); as ideologias (democracia, plutocracia, etc.).

Das categorias de forma (modo de tratar o assunto) merecem referências as do estudo de Wyant e Herzog, sobre a correspondência dirigida aos membros do Congresso americano, a saber: ameaças, cumprimentos, críticas, oferecimentos de auxílio.

As categorias de apreciação envolvem a tomada de posição pessoal do signatário, em torno dos valores referidos no documento: aprovação, desaprovação, pessimismo, otimismo, etc. Kaplan e Golsen sugeriram diferentes niveis: atitude fortemente positiva, atitude simplesmente positiva, atitude equilibrada, atitude neutra, etc.

As outras categorias dispensam comentários. O que é importante advertir é que a utilização desta ou daquela categoria geral deve ser acompanhada de verificação ou de teste de fidelidade (independência em relação à personalidade do analista) e de validade (conceitos precisos nas definições). Podem ser formuladas subcategorias adaptadas aos documentos ou às unidades de análise em questão.

\section{III - Prática da Análise do Conteúdo. Mensagens dirigidas à Administração Pública. Simulação.}

As mensagens dirigidas à Administração Pública podem proceder das mais variadas origens e dos mais diferentes signatários e tratar de toda a gama de assuntos em que incide a ação dos poderes públicos.

As categorias de pessoas, entretanto, embora potencialmente infinitas, limitam-se, em sintese, a apenas duas: pessoas fisicas e pessoas jurídicas. As regiões geo-econômicas e o exterior também circunscrevem as categorias de origem: Norte, Nordeste, Sudeste, Sul e Centro-Oeste, conforme a classificação do Instituto Brasileiro de Geografia e Estatística, no Brasil.

As categorias de matéria estão automaticamente determi. nadas, eis que cada missiva deverá ser encaminhada ao Ministério do respectivo assunto, e estes, formando subcategorias, podem ser grupados em áreas ou categorias apropriadas. Tais áreas, de acordo com o Decreto-lei n. ${ }^{\circ} 200$, de 25.2.67, com as modificações adaptadas à análise, foram assim resumidas: 
AREA POLITICA

Justiça

Ordem Jurídica

Segurança Interna

Administração Penitenciária

Ministério Público

Documentação Oficial

\section{Relações Exteriores}

Política Internacional

Relações Diplomáticas e Consulares

Negociações Multilaterais

Cooperação Internacional

\section{ÁREA PSICOSSOCIAL}

Saúde

Política Nacional de Saúde

Atividades Médicas e Para-Médicas

Ação Preventiva

Controle de Drogas, Medicamentos e Alimentos

Pesquisas Médico-Sanitárias

\section{Habitação e Urbanismo}

Migrações Internas

Engenharia Sanitária

Proteção Contra Secas e Inundações

Assistência em Calamidades Públicas

Assistência ao Indio

Assistência aos Municípios

Territórios Federais

Programa Nacional de Habitação

\section{Educação}

Ensino. Magistério

Cultura - Letras e Artes

Desportos

Patrimônio Histórico, Arqueológico, Científico

Cultural e Artístico 


\section{Trabalho e Previdência Social}

Organização Profissional e Sindical

Mercado de Trabalho

Política Salarial

Previdência e Assistência Social

Política de Imigração

Ministério Público Junto à Justiça do Trabalho

\section{ÁREA ECONOOMICA}

\section{Infra-estrutura}

Transportes

Comunicações

Minas e Energia

Geologia, Recursos Minerais e Energéticos

Regime Hidrológico

Mineração

Indústria do Petróleo

Indústria de Energia Elétrica e Eletrônica

\section{Setores}

\section{Agricultura}

Agropecuária. Caça. Pesca.

Recursos Naturais Renováveis

Organização da Vida Rural. Reforma Agrária

Meteorologia e Climatologia

Vigilância e Defesa Sanitária Animal e Vegetal

Indústria e Comércio

Comércio

Seguros Privados e Capitalização

Turismo

Pesquisa e Experimentação Tecnológica

Propriedade Industrial, Registro do Comércio e Metrologia

\section{Finanças}

Planejamento

Plano Geral de Governo

Pesquisas Sócio-Econômicas 


\title{
Orçamentação \\ Assistência Técnica Internacional \\ Estatística e Cartografia \\ Organização Administrativa
}

\section{Fazenda}

\author{
Moeda e Crédito \\ Administração Tributária \\ Administração Financeira \\ Contabilidade e Auditoria \\ Serviços Gerais
}

Quanto às categorias de apreciação, isto é, quanto aos juízos de valor emitidos pelas pessoas físicas e jurídicas em torno das matérias política, psicossocial ou econômica, acima sumariadas, tê-mo-las assim resumidas: favorável, desfavorável ou postulante, excetuada a categoria protocolar.

Eis, portanto, as categorias de pessoas, de origem, de matéria e de apreciação, organizadas com auxílio da teoria e bastante caracterizadas para a análise do conteúdo que se deseje. Os testes de fidelidade e de validade desenvolvem-se sem maiores dificuldades, porquanto, no caso (que incide no Plano de Administração Pública), estão suficientemente definidas e determinadas, legal e doutrinariamente, as categorias selecionadas.

A classificação das unidades de análise - basicamente a carta - dentro daquelas categorias, pode assim ser processada por equipes e mediante operações de codificação, perfuração, separação, quantificação e tabulação.

\section{IV - CONCLUSÕES}

O resultado de uma análise do conteúdo das mensagens que fossem dirigidas à Administração Pública poderia assumir, em termos percentuais e simulados, a configuração abaixo:

\section{Categorias de Pessoas}

Físicas $\ldots \ldots \ldots \ldots \ldots \ldots \ldots \ldots \ldots \ldots \ldots \ldots \ldots \ldots \ldots \ldots \ldots \ldots \ldots \ldots \ldots$
Jurídicas $\quad \ldots \ldots \ldots \ldots \ldots \ldots$ 
Categorias de Origem

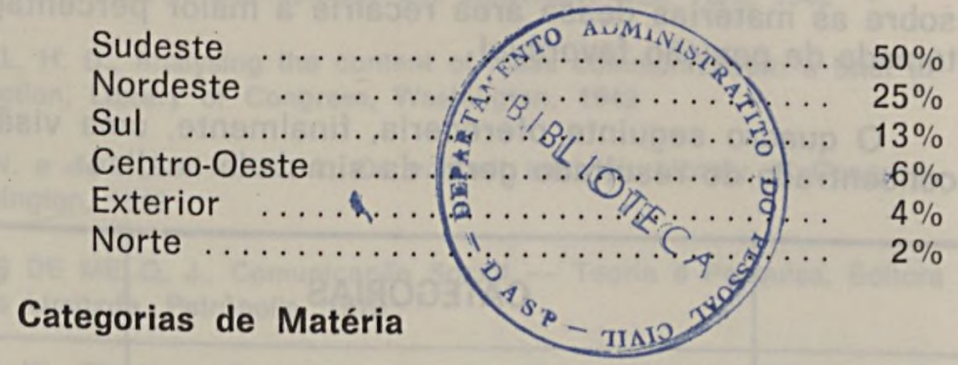

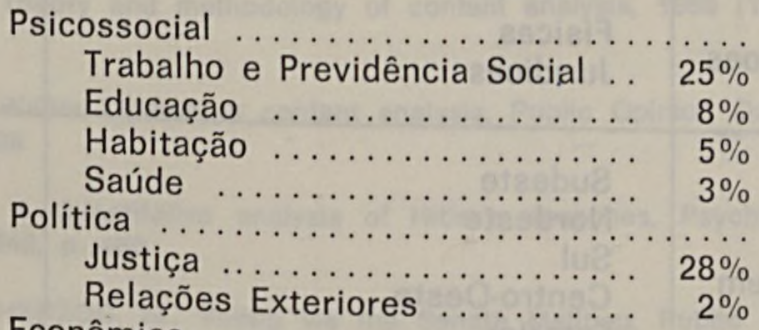

Econômica

$41 \%$

Finanças (Fazenda e Planejamento) ................ 16\%

Setores

Infra-estrutura

$4 \%$

\section{Categorias de Apreciação}

Postulante

Psicossocial

Política

$23 \%$

Econômica

Favorável

$30 \%$

$29 \%$

Psicossocial

Política

$16 \%$

$15 \%$

Econômica

$10 \%$

$24 \%$

Desfavorável

$54 \%$

Psicossocial

$22 \%$

Política

$8 \%$

Econômica

Verificar-se-ia, nessa hipótese, que o maior indice de cartas partiria das pessoas físicas e do Sudeste do Pais. A área psicossocial dominaria o conteúdo do conjunto de mensagens, evidentemente por força das problemáticas do ensino, da habitação, do 
salário e da Previdência Social, comuns a todos os países. Ainda sobre as matérias dessa área recairia a maior percentagem de tomada de posição favorável.

O quadro seguinte ofereceria, finalmente, uma visão mais concentrada do resultado geral da simulada análise:

\begin{tabular}{|c|c|c|}
\hline & CATEGORIAS & $\%$ \\
\hline Pessoas & $\begin{array}{l}\text { Fisicas } \\
\text { Juridicas }\end{array}$ & $\begin{array}{l}67 \\
33\end{array}$ \\
\hline Origem & $\begin{array}{l}\text { Sudeste } \\
\text { Nordeste } \\
\text { Sul } \\
\text { Centro-Oeste } \\
\text { Exterior } \\
\text { Norte }\end{array}$ & $\begin{array}{r}50 \\
25 \\
13 \\
6 \\
4 \\
2\end{array}$ \\
\hline Matéria & $\begin{array}{l}\text { Psicossocial } \\
\text { Política } \\
\text { Econômica }\end{array}$ & $\begin{array}{r}41 \\
30 \\
29\end{array}$ \\
\hline Posição & $\begin{array}{l}\text { Postulante } \\
\text { Favorável } \\
\text { Desfavorável }\end{array}$ & $\begin{array}{l}54 \\
24 \\
22\end{array}$ \\
\hline
\end{tabular}

\section{BIBLIOGRAFIA ESPECIALIZADA}

ALLPORT, G. W., The use of personal documents in psychological science, New York, 1942

BERELSON, B., Content analysis in communication research, New York, 1952 (obra clássica na análise documental)

BOULANGER, J., Les allocution radioffusées du président Mendés - France, Rev. franc. de science polit., 1956, p. 851

DUVERGER, Maurice. Análise de Documentos, in Ciência Politica, teoria e método, Zahar Editores, Rio, 1962, p. 101 e ss.

R. Serc. Públ., Brasília, 108 (1): jan/abr. 1973 
GOTTSCHALK, L., KLUCKHON, C. e ANGEL, R., The use of personal documents in history, anthropology and sociology, New York, 1945

LASSWELL, H. D., Analysing the content of mass communication: a brief introduction, Library of Congress, Washington, 1942

LEITES, N. e de SOLA POOL, I., On content analysis, Library of Congress, Washington, 1942

MARQUES DE MELO, J., Comunicação Social - Teoria e Pesquisa, Editora Vozes Limitada, Petrópolis, 1970

SCHULTZ, W., Theory and methodology of content analysis, 1950 (Tese de doutorado)

WEINGAS, D., Walter Lipman: a content analysis, Public Opinion Quarterly, 1950, p. 296

WHITE, R. K., A Quantitative analysis of Hitler's speeches, Psychological Bulletin, 1942, p. 486

WYANT, R. e HERZOG, H., Voting via the Senate Mailbag, Public Opinion Quarterly (Análise da correspondência de um Membro do Congresso Americano). 


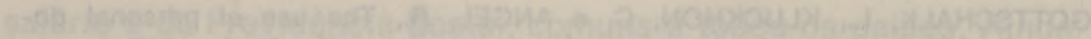

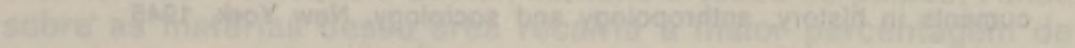

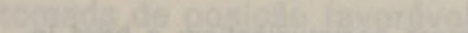

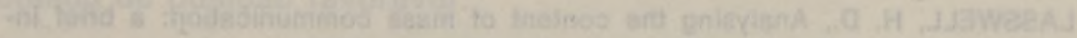

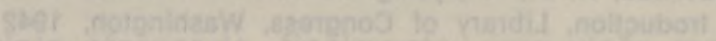

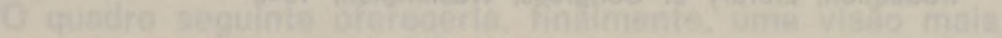

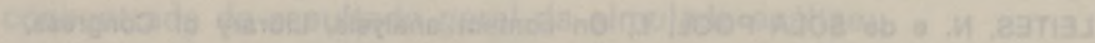
Bher motaniflesW

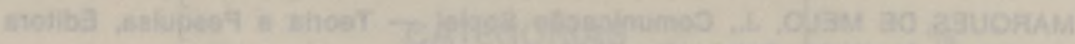

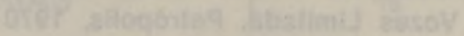

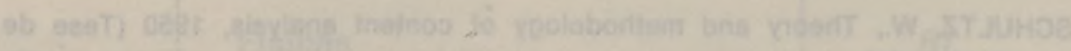

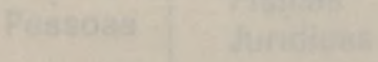

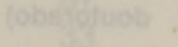

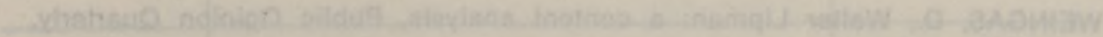

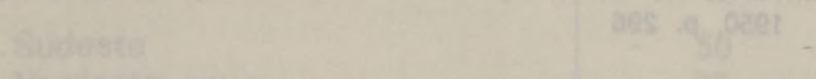

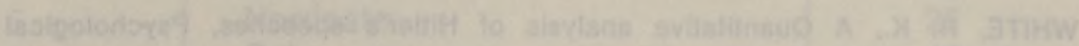

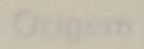 Sit

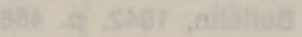

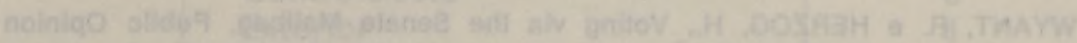

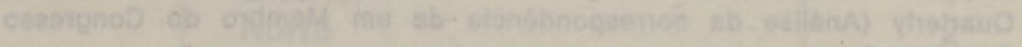

-

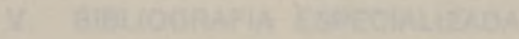

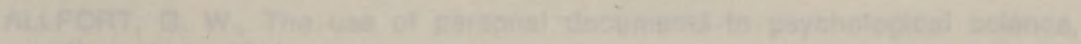

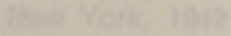

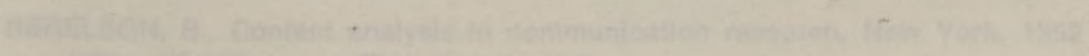

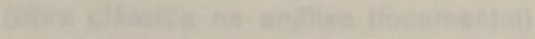

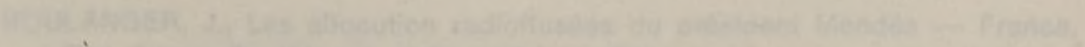
T.

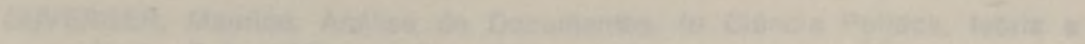

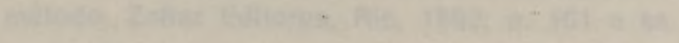

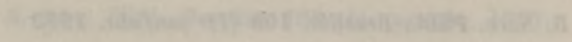

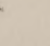

